\title{
Functional Assessment for Decision-Making Regarding Return to Sports Following ACL Reconstruction: A Comparison of Football Players with Normative Data
}

\author{
Fischer F1, Gföller $\mathbf{P}^{1,2}$, Hoser $\mathrm{C}^{1,2}$, Gatterer $\mathbf{H}^{3}$, Raschner $\mathrm{C}^{4}$, Fink $\mathrm{C}^{1,2,5 *}$ \\ ${ }^{1}$ FIFA Medical Centre of Excellence Innsbruck/ Tirol, Austria \\ ${ }^{2}$ Gelenkpunkt - Sports and Joint Surgery, Olympiastraße 39, 6020 Innsbruck, Austria \\ ${ }^{3}$ Institute of Mountain Emergency Medicine, EURAC Research, Bolzano, Italy \\ ${ }^{4}$ Department of Sport Science, University of Innsbruck, Fürstenweg 185, 6020 Innsbruck, Austria \\ ${ }^{5}$ Research unit of Orthopaedic Sports Medicine and Injury Prevention, ISAG/UMIT, Eduard-Wallnöfer-Zentrum 1, 6060 Hall in Tirol, Austria \\ ${ }^{*}$ Correspondence to: Christian Fink, Gelenkpunkt - Sports and Joint Surgery, Olympiastraße 39, 6020 Innsbruck; Tel: +43 512 397030, Fax: +43 512 39703020; \\ E-mail: c.fink@gelenkpunkt.com
}

Received: July 13, 2018; Accepted: July 20, 2018; Published: July 25, 2018;

\section{Abstract}

\section{Context}

In order to objectively evaluate knee function after anterior cruciate ligament reconstruction and a patient's possible return to sport, a standardized and easy-to-use test battery has been developed.

\section{Objective}

The aim of this study was to compare the outcomes of a test battery in football players with data of are ference group.

\section{Design}

Cross-sectional study.

\section{Setting}

Strength training facility and university laboratory.

\section{Participants}

Thirty-four male football players $(21.4 \pm 4$. 1years, $179.9 \pm 4.9 \mathrm{~cm}, 73.6 \pm 6.1 \mathrm{~kg})$ of a professional football club and a cohort $(\mathrm{n}=52)$ of healthy, physical active population $(24.8 \pm$ 3years, $179.0 \pm 5.7 \mathrm{~cm}, 74.8 \pm 6.3 \mathrm{~kg})$ were included in the study.

\section{Intervention}

Participants completed a test battery consisting of seven functional tests; a two-legged and one-legged stability test, a two-legged and one-legged counter movement jump with height and power calculations, speedy jumps, plyometric jumps and a quick feet test.

\section{Main outcome measures}

Balance score, jump height, contact time, time to complete jump tasks.

\section{Results}

Football players differed in regard to jump height in the two-legged counter movement jump $(45.2 \pm 5 \mathrm{~cm}$ vs. $42.0 \pm 6 \mathrm{~cm} ; \mathrm{p}=0.009)$ and the one-legged counter movement jump with the non-dominant leg $(25.0 \pm 3 \mathrm{~cm}$ vs. $29.4 \pm 6 ; p<0.001)$, and showed higher jump heights in the plyometric jumps (39. $0 \pm$ $6 \mathrm{~cm}$ vs. $33.5 \pm 9 \mathrm{~cm} ; \mathrm{p}=0.001)$. Contact time was shorter in the reference group $(141 \pm 22 \mathrm{~ms}$ vs. $186 \pm 36 \mathrm{~ms} ; \mathrm{p}<0.001)$, whereas Football players completed the jump parkour quicker.

\section{Conclusions}

A higher jump and agility test performance in football players is indicating training specific adaptations related to the demand of the game. Establishing football specific norm data might be of interest for future research.

Keywords: Football (soccer), Test Battery, Return to play, Performance Diagnostic, Hop performance, Knee function 


\section{Introduction}

After rupture of the Anterior Cruciate Ligament (ACL), most athletes are advised to undergo ACL reconstruction (ACLR) when they wish to continue in their sports $[1,2]$. In a high risk full contact sport such as football, ACLR rate is high [3]. Clearance for most athletes after ACLR is typically given within the first year after surgery $[4,5]$. In post-surgery treatment and rehabilitation, every individual needs closer examination, as longstanding deficits in strength and neuromuscular control of the lower extremity were reported on average 3 years after an ACLR [6]. Research has been intensified in the last decade and training methods were improved, however, injury incidence remains on an unchanged level [7]. Risk factors for a rerupture or a secondary injury of the lower extremity may be attributed to deficits in muscle function compared to the pre-injury level [8]. Athletes who do not successfully return to their pre injury level of competition after an ACL injury is another aspect $[1,4,9]$.

Many test batteries have been developed in the last decade, in order to assess functional capabilities in ACLR patients and to support decision-making for return to sports [10-13]. Usually they contain isokinetic strength tests, hop tests for height and distance, side hop tests, and jump- landing tasks $[2,10,11,14,15]$. A standardized and easy-to-use test battery has been developed to support clinicians in their decision regarding a patient's return to sport, enabling an objective evaluation of knee function. $[12,13]$ This test battery includes seven functional tests, norm data from healthy individuals were also established and the tests showed a moderate-to-high reliability [13]

However, it is questionable if norm data from healthy, athletically active individuals also apply for football specific groups. Therefore, norms should be available for every specific sport group. Additionally, if an athlete's performance outcome of the test battery is registered regularly, personal performance data are available in the case of an injury. The purpose of this study was to compare norm data of a test battery with the performance data of football players achieved with the same test battery. It was hypothesized that football players had better outcomes in the functional tests than norm data from healthy and physical active individuals, which would argue in favor to the need of population specific norms.

\section{Materials and methods}

A two cohort design was used to evaluate data from a functional test battery in football players with normative data. Data for the normative cohort were obtained from a previous study which followed a comparable methodological approach as the present investigation (shortly outlined below) [13]. Only data from male participants were used for data analysis. For the football cohort, a total of 34 male, healthy football players aged between 17 and 32 years participated in the study. Detailed description of the participants is shown in Table 1.

Study sample compromised two teams of one professional football club playing in the second highest national league and in the highest amateur league ( $3^{\text {rd }}$ tier). Sample size resulted from the available players of the team squad. Functional testing was conducted in the fitness facilities prior to team training with at least 72 hours between the last match. Participants completed a standardized warm up program on a stationary bicycle (8 minutes cycling with 1 Watt/ $\mathrm{kg}$ body weight) and 2 minutes of rope skipping at their own pace. When needed, participants were allowed to conduct squats, lunges, dynamic stretching prior to testing. To determine the dominant leg participants were asked which leg they preferred for kicking, which leg they preferred for jumping and a push-forward test (participants were pushed from behind and the leg which they used in the first step was recorded) was conducted. Dominant side was defined when at least two test matched accordingly. All subjects were evaluated by the same examiners. Subjects wore their training clothes without shoes and socks. The study was approved by the institutional review board for ethical questions in science of the University of Innsbruck (9/2015) and was conducted according to the Declaration of Helsinki [16]. The study staff was trained in good clinical practice and all participants granted written informed consent prior to participation.

Table 1. Descriptive participant demographics.

\begin{tabular}{|c|c|c|c|c|}
\hline & $\begin{array}{c}\text { All } \\
\text { participants } \\
(\mathbf{N}=\mathbf{8 5})\end{array}$ & $\begin{array}{c}\text { Football players } \\
(\mathbf{n}=\mathbf{3 4})\end{array}$ & $\begin{array}{c}\text { Norm } \\
\text { population } \\
(\mathbf{n}=\mathbf{5 1})\end{array}$ & p-value \\
\hline $\begin{array}{c}\text { Age } \\
(\text { years })\end{array}$ & $23.4 \pm 4$ & $21.3 \pm 4$ & $24.8 \pm 3$ & $<0.001$ \\
\hline $\begin{array}{c}\text { Height } \\
(\mathrm{cm})\end{array}$ & $179.4 \pm 5$ & $180.0 \pm 5$ & $179.0 \pm 6$ & n.s. \\
\hline Mass (kg) & $74.3 \pm 6$ & $73.4 \pm 6$ & $74.8 \pm 6$ & n.s. \\
\hline $\begin{array}{c}\text { BMI (kg/ } \\
\left.\mathrm{m}^{2}\right)\end{array}$ & $22.7 \pm 1$ & $22.6 \pm 1$ & $22.7 \pm 2$ & n.s. \\
\hline
\end{tabular}

\section{Functional Testing}

The Back in Action (BIA) test battery (CoRehab, Trento, Italy) is designed for sportive users in healthy conditions or in any phase of a recovery period after an injury. The test measures dynamically the balance, the speed and the strength in respect to normative data from a large group of healthy individuals. As a further optional outcome, a back to sport indicator (BIA indicator) is also provided. This BIA indicator compares the test score with the individual score of an athlete if the test battery has been conducted pre-injury, otherwise a comparison with an age-matched reference group will be made. The test battery "Back in Action" can be accomplished within 45 min, needs little equipment and only one room. It consisted of the following subtests: a two-legged (TL-ST) and one- legged stability test (OL-ST), a two-legged (TL$\mathrm{CMJ}$ ) and one-legged counter movement jump with height and power calculations (OL-CMJ), speedy jumps (OL-SY), plyometric jumps (TL-PJ) and a quick feet test (TL-QFT) $[12,13]$. The TL-ST and the OL-ST is used to assess postural control and the tests were performed on an MFT Challenge Disc (TST Trendsport, Grosshöflein, Austria) connected to a PC. The disc is free to move in all directions. While balancing on the disc, the software provides instant feedback about the position of the disc. To avoid the influence of different shoe types, all trials were performed without shoes. Subjects were instructed to stand in the center with their arms at their sides [13]. In TL-ST, subjects had to stand with both legs on the disc while maintaining their balance for 30 seconds. Data collection was immediately stopped in the case of a loss of balance whereas the OL-ST was performed with 
one leg. The subject was not allowed to stabilize the raised leg against the plate or standing leg [13]. In the TL-CMJ subjects quickly bent their knees from an upright position and then immediately jumped upward, attempting to maximize their height. During this hop, arms were placed on the hips while the OL-CMJ was similar to the two-leg test, but this test was performed with one leg [13]. In the TL-PJ, the subject had to perform three consecutive two-leg jumps, focusing on a maximum jump height and a fast ground contact time. Arms could be used to assist with the jump [13]. For the OL-SY, the Speedy Basic Jump Set (TST Trendsport, Grosshöflein, Austria) was used to create the jump coordination path. The subjects performed one-footed jumps through the course of red (forward backward-forward jumps) and blue (sideway jumps) hurdles, completing 16 jumps. This had to be performed as quickly as possible by jumping on one leg without a rest between the hurdles. Twisting of the hip was not allowed, and the test was immediately stopped when the raised leg touched the ground or the subject had direct contact with the speedy basic jump hurdles. The test was performed for both legs separately. Time was measured using a stopwatch beginning as soon as the subject started to jump and ending when players reached the finish line with one leg. The mean value was recorded for each jump [13]. For the TL-QFT, the Speedy Basic Jump Set (TST Trendsport, Grosshöflein, Austria) was also used to create a tapping zone. The subject had to step in and out with one foot after the other until 15 repetitions were completed. One repetition was finished when the starting leg returned to its initial position. The test was stopped if the subject reversed the order of the steps. Arms could be used to maintain balance, and stepping on the speedy pole was not allowed [13]. Again, time was measured using a stopwatch. In TL-ST and OL-ST, low values represent a better outcome. For the TL-CMJ, the OL-CMJ, and the TL-PJ higher values are preferable, whereas contact time in TL-PJ should be as short as possible. For OLSY and TL-QFT quick times represent a better result. The order of the applied tests was held constant between the two cohorts. None of the cohorts conducted a special familiarization session, however the first trial in each subtest served as a test trial and the results were not recorded. Test-retest reliability for each sub-test was determined using the intraclass correlation coefficient (ICC 1/1) in the one-way random effects model. The ICC indicated a high reproducibility for the TL-CMJ (0. 921) and a moderate reproducibility for the TL-ST (0. 688). All other tests showed good test-retest reliabilities [13]. With respect to the jump tests, the reference group was measured with the Myotest System (Myotest, Sion, Switzerland), whereas the football players were measured with the accelerometer device and its software solution provided from the BIA test battery company (CoRehab, Trento, Italy). Comparison of the two jump sensors detected a mean error of approximately $0.7 \mathrm{~cm}$, and a maximum error of $1.6 \mathrm{~cm}$ in the countermovement jump [17].

\section{Statistical analysis}

All variables were displayed descriptively including mean, standard deviation (SD), 95\% confidence interval (95\% CI) and proportion, respectively. Normality of distribution was checked with the Kolmogorov-Smirnov test and box plots. Independent t-tests were used to compare data of the football players with data of the reference group. Statistical significance was accepted for $\mathrm{p} \leq 0$. 05. All statistical analyses were performed with IBM SPSS Statistics for Windows, Version 24. 0 (Armonk, NY: IBM Corp). G*Power 3. 1. 9. 2 (Franz Paul, Kiel, Germany) was used to calculate Cohens d effect size.

\section{Results}

Football player and the normal population showed a similar body stature ( $p>0.05)$, however, football players on average were somewhat younger than the normal population $(\mathrm{p}<0.001$, Table 1$)$. A significant difference in the TL-CMJ for height with higher values in the norm population $(p=0.009)$ were measured. Higher values in football players were found in the OL-CMJ for height in the dominant leg $(p<0.001)$. Football players jumped significantly higher in the TLPJ $(\mathrm{p}=0.002)$, whereas the norm population showed significantly shorter contact time $(p<0.001)$. OL-SY showed significant differences in the dominant $(p=0.022)$ and the non-dominant leg $(p=0.018)$ with quicker times in football players. No differences in the other functional tests were present. Detailed results of the functional tests are displayed in Table 2.

\section{Discussion}

The main finding of this study is that several tests differed between football players and the reference group. Participants of the healthy and athletically active reference group jumped significantly higher than football players in the TL-CMJ, although power output showed no differences. Football players jumped significantly higher in the OL-CMJ with the non-dominant leg, and higher power output were observed in football players in both the dominant and nondominant leg. They showed higher jump heights in the plyometric jumps, however, contact time was shorter in the norm population. Football players completed the jump parkour in a faster time, while no differences in the quick feet test were present.

For sports in general, and especially for injury protection, it is important to produce high force quickly. [18] With its dynamic explosive force production capacity, the CMJ is used to possibly assess knee extensor strength. $[19,20]$ In the present study, higher jump heights in the TL-CMJ were recorded in the reference group. These results are somehow unexpected, as the football cohort consisted of professional and semi-professional football players with a daily training regime and at least $8 \mathrm{~h} /$ week or more of training. Moreover, professional football squad members are typically more exposed to physical testing [21] and thus should be experienced with testing methods, especially with the countermovement jump. The use of two different jump sensors might have led to this apparent discrepancy. Additionally, it could be argued that the TL-CMJ as a test is not able to discriminate football players from a healthy and physical active population. However, football players showed higher jump values in the one-legged CMJ, supporting the assumption that football players reach higher values due to the specifity of training and the physical demand of their sport. 
Fink C (2018) Functional Assessment for Decision-Making Regarding Return to Sports Following ACL Reconstruction: A Comparison of Football Players with Normative Data

Table 2. Results of the test battery.

\begin{tabular}{|c|c|c|c|c|c|c|}
\hline & $\begin{array}{c}\text { All } \\
\text { participants ( } \mathbf{N} \\
=\mathbf{8 5})\end{array}$ & $\begin{array}{c}\text { Football } \\
\text { players }(n=34)\end{array}$ & 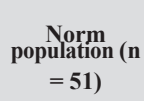 & $\begin{array}{l}\text { Football vs. } \\
\text { Norm }\end{array}$ & p-value & Effect size d \\
\hline & mean \pm SD & mean $\pm \mathrm{SD}$ & mean $\pm \mathrm{SD}$ & $\Delta(95 \% \mathrm{CI})$ & & \\
\hline \multicolumn{7}{|c|}{ Two-legged stability test } \\
\hline & $2.71 \pm 0.5$ & $2.73 \pm 0.5$ & $2.69 \pm 0.5$ & $\begin{array}{c}0.04 \\
( \pm 0.22)\end{array}$ & n.s. & 0.08 \\
\hline \multicolumn{7}{|l|}{ One- legged stability test } \\
\hline Dominant leg & $2.5 \pm 0.4$ & $2.53 \pm 0.4$ & $2.48 \pm 0.5$ & $\begin{array}{c}0.05 \\
( \pm 0.20)\end{array}$ & n.s. & 0.11 \\
\hline Non-dominant leg & $2.49 \pm 0.4$ & $2.48 \pm 0.4$ & $2.49 \pm 0.4$ & $\begin{array}{l}-0.01 \\
( \pm 0.17)\end{array}$ & n.s. & 0.025 \\
\hline \multicolumn{7}{|c|}{ Two-legged counter movement jump } \\
\hline Height (cm) & $43.9 \pm 6$ & $42.0 \pm 6$ & $45.2 \pm 5$ & $\begin{array}{c}-3.24 \\
( \pm 2.42)\end{array}$ & 0.009 & 0.58 \\
\hline \multicolumn{7}{|c|}{ One-legged counter movement jump with height calculation $(\mathrm{cm})$} \\
\hline Dominant leg & $28.3 \pm 5$ & $29.3 \pm 5$ & $27.6 \pm 4$ & $\begin{array}{c}1.62 \\
( \pm 1.97)\end{array}$ & n.s. & 0.38 \\
\hline Non-dominant leg & $26.8 \pm 5$ & $29.4 \pm 6$ & $25.0 \pm 3$ & $\begin{array}{c}4.37 \\
( \pm 2.13)\end{array}$ & $<0.001$ & 0.93 \\
\hline \multicolumn{7}{|c|}{ Plyometric jumps } \\
\hline Height $(\mathrm{cm})$ & $35.7 \pm 8$ & $39.0 \pm 6$ & $33.5 \pm 9$ & $\begin{array}{c}5.51 \\
( \pm 3.44)\end{array}$ & 0.001 & 0.72 \\
\hline Time (ms) & $159 \pm 36$ & $186 \pm 36$ & $141 \pm 22$ & $\begin{array}{c}44.5 \\
( \pm 12.7)\end{array}$ & $<0.001$ & 1.5 \\
\hline $\begin{array}{l}\text { Reactive strength index } \\
(\mathrm{mm} / \mathrm{ms})\end{array}$ & $2.3 \pm 0.5$ & $2.1 \pm 0.3$ & $2.4 \pm 0.5$ & $\begin{array}{c}-0.24 \\
( \pm 0.19)\end{array}$ & 0.011 & 0.73 \\
\hline \multicolumn{7}{|c|}{ Speedy jumps (s) } \\
\hline Dominant leg & $5.71 \pm 0.7$ & $5.51 \pm 0.5$ & $5.84 \pm 0.7$ & $\begin{array}{c}-0.33 \\
( \pm 0.28)\end{array}$ & 0.022 & 0.54 \\
\hline
\end{tabular}

Although better proprioception in Olympic-level male football players compared to sex-matched non-athletes were found in a previous study [22], no statistically significant differences between football players and the reference group existed in the stability tests. The stability test used in this evaluation might not have been able to show possible differences as a rather general stability index is assessed with the test that might not necessarily represent specific adaptations to football training and play.

In regard to the plyometric jumps, football players showed higher jump, however, contact time was shorter in the reference group. Although both cohorts have been instructed the same way (jump as high as you can with as little contact time as possible), football players have intuitively increased contact time to increase force production and to consequently achieve a higher jump height. The Plyometric jump test reproduces the stretch-shortening cycle, which is important for movement initiation and acceleration performance [23]. Muscletendon behavior of the agonists is optimized with alteration in the neuromuscular activity and an increase in tendon stiffness during plyometric exercises, while there is a decrease in the neuromuscular activity of antagonists during a counter movement [24]. In football, players are required to repeatedly perform short, explosive efforts such as accelerations and decelerations during change of direction [25]. Reactive strength, specifically to change rapidly from eccentric to concentric action, affects these agility performance actions [23, 26]. As these actions are repeatedly linked to non-contact ACL injuries [25], the focus in football players should be on developing a better muscle activation pattern and therefore reducing contact time while maintaining the jump height. In the speedy jump test, football players showed faster time values than the reference group for both legs. Football training is aimed to develop speed and reactivity, which arguably may influence speedy jump test outcomes. The specific training regime adopted by football teams thus might explain the better speed jump test performance compared to the reference population. As this test is performed with one leg, the test 
provides single leg performance parameters and might also be useful to detect bilateral differences in the operated and non-operated leg. This might be of special importance when considering that long term deficits in strength and neuromuscular control of the lower extremity after an ACLR exist [6] which might be risk factors for a re-rupture or a secondary injury of the lower extremity [8]. Assessment of maximum speed in lower limb movement is typically recorded by a foot tapping test [27], with only little equipment the quick feet test offers a comparable result. As no differences between football players and the reference group were found in the quick feet test, it has to be questioned if this test specifically covers football relevant skills.

There are several advantages when clinically assessing functional performance. When it comes to detect possible asymmetries and therefor adapt training methods, objective data are advantageous. The test battery assesses balance, speed and strength, and a high level of both strength and power variables are preferable in football, on the one hand for a possible injury risk reduction, on the other hand for allowing more powerful jumps, kicks, tackles, and sprints [28, 29]. Once completed pre-injury, an objective evaluation about the functional readiness to return to sports after ACLR is possible. Using the amount of time postoperatively often as the only criterion [30,31] and still lacking consensus for clearing patients to unrestricted sports activities after ACLR $[2,32]$, this test battery may support clinicians in their decision making regarding return to sports.

Some limitations of the study have to be acknowledged. Reference data were obtained from a prior study under slightly different conditions as outlined before. In this regard the usage of a different jump sensor in each cohort has to be recognized as a possible source of deviations in jump height assessment for the two-legged countermovement jump. However, comparable results were obtained in the evaluation of the two jump sensors. Further, football players were playing in the second and the third tier. Thus as data from amateur football players at a lower performance level were not recorded, the values established in this study are only valid for the specific group tested.

\section{Conclusion}

A comparison of the test battery in football players and the reference group detected several differences in performance. Establishing football specific norm data with this easy to use test battery might be of interest for future research. The test battery delivers valuable information about physical capabilities and sideto-side differences. Once completed pre-injury, functional readiness to return to sports may be evaluated objectively with the player's data. Collecting pre-injury data in order to optimize the course of rehabilitation and decision-making for return to sports should be established as a best-practice strategy.

\section{Conflict of Interest}

The authors declare that they have no conflict of interest related to this study.

\section{Acknowledgement}

The study group would like to thank all of the study participants for their efforts. Special thanks to Karl Schwarzenbrunner for functional testing.

\section{References}

1. Balazs GC, Pavey GJ, Brelin AM, Pickett A, Keblish DJ et al (2015) Risk of Anterior Cruciate Ligament Injury in Athletes on Synthetic Playing Surfaces: A Systematic Review. Am J Sports Med 43: 1798-1804. [crossref]

2. Gokeler A, Welling W, Zaffagnini S, Seil R et al (2017) Development of a test battery to enhance safe return to sports after anterior cruciate ligament reconstruction. Knee Surg Sports Traumatol Arthrosc 25: 192-199. [crossref]

3. Waldén M, Hägglund M, Magnusson H, Ekstrand J (2016) ACL injuries in men's professional football: a 15 -year prospective study on time trends and return-to-play rates reveals only $65 \%$ of players still play at the top level 3 years after ACL rupture. Br J Sports Med 50: 744-750

4. Ardern CL, Webster KE, Taylor NF, Feller JA (2011) Return to the preinjury level of competitive sport after anterior cruciate ligament reconstruction surgery: twothirds of patients have not returned by 12 months after surgery. Am J Sports Med 39: 538-543. [crossref]

5. Myklebust G, Bahr R (2005) Return to play guidelines after anterior cruciate ligament surgery. Br J Sports Med 39: 127-131. [crossref]

6. Otzel DM, Chow JW, Tillman MD (2015) Long-term deficits in quadriceps strength and activation following anterior cruciate ligament reconstruction. Phys Ther Sport 16: $22-28$

7. Alentorn-Geli E, Mendiguchía J, Samuelsson K, Musahl V, Karlsson J, Cugat R, Myer GD (2014) Prevention of non-contact anterior cruciate ligament injuries in sports. Part II: Systematic review of the effectiveness of prevention programmes in male athletes. Knee Surg Sports Traumatol Arthrosc 22: 16-25

8. Thomeé R, Kaplan Y, Kvist J, Myklebust G, Risberg MA, Theisen D, Tsepis E, Werner S, Wondrasch B, Witvrouw E (2011) Muscle strength and hop performance criteria prior to return to sports after ACL reconstruction. Knee Surg Sports Traumatol Arthrosc 19: 1798-1805

9. Ardern CL, Webster KE, Taylor NF, Feller JA (2011) Return to sport following anterior cruciate ligament reconstruction surgery: a systematic review and metaanalysis of the state of play. Br J Sports Med 45: 596-606

10. Gustavsson A, Neeter C, Thomee P, Silbernagel KG, Augustsson J, Thomee R, Karlsson J (2006) A test battery for evaluating hop performance in patients with an ACL injury and patients who have undergone ACL reconstruction. Knee Surg Sports Traumatol Arthrosc 14: 778-788

11. Neeter C, Gustavsson A, Thomeé P, Augustsson J, Thomeé R, Karlsson J (2006) Development of a strength test battery for evaluating leg muscle power after anterior cruciate ligament injury and reconstruction. Knee Surg Sports Traumatol Arthrosc 14: 571-580

12. Herbst E, Hoser C, Hildebrandt C, Raschner C, Hepperger C, Pointner H, Fink C (2015) Functional assessments for decision-making regarding return to sports following ACL reconstruction. Part II: clinical application of a new test battery. Knee Surg Sports Traumatol 287 Arthrosc 23: 1283-1291

13. Hildebrandt C, Müller L, Zisch B, Huber R, Fink C, Raschner C (2015) Functional assessments for decision-making regarding return to sports following ACL reconstruction. Part I: development of a new test battery. Knee Surg Sports Traumatol Arthrosc 23: 1273-1281

14. Augustsson J, Thomeé R, Karlsson J (2004) Ability of a new hop test to determine functional deficits after anterior cruciate ligament reconstruction. Knee Surg Sports Traumatol 293 Arthrosc 12: 350-356

15. Reid A, Birmingham TB, Stratford PW, Alcock GK, Giffin JR (2007) Hop testing provides areliable and valid outcome measure during rehabilitation after anterior cruciate ligament reconstruction. Phys Ther 87: 337-349.

16. World Medical Association (2013) Declaration of Helsinki. Ethical principles for medical research involving human subjects. JAMA 310: 2191-2194.

17. Milosevic B, Farella E (2015) Wearable Inertial Sensor for Jump Performance Analysis. Proc 2015 Work Wearable Syst Appl 15-20.

18. Ageberg E, Roos HP, Silbernagel KG, Thomeé R, Roos EM (2009) Knee extension and flexion muscle power after anterior cruciate ligament reconstruction with patellar tendon graft or hamstring tendons graft: A cross-sectional comparison 3 years post surgery. Knee Surg Sports Traumatol Arthrosc 17: 162-169.

19. Fischer F, Blank C, Dünnwald T, Gföller P, Herbst E et al (2017) Isokinetic Extension Strength Is Associated With Single-Leg Vertical Jump Height. Orthop J Sports Med 5: 2325967117736766. [crossref] 
Fink C (2018) Functional Assessment for Decision-Making Regarding Return to Sports Following ACL Reconstruction: A Comparison of Football Players with Normative Data

20. Pääsuke M, Ereline J, Gapeyeva H (2001) Knee extension strength and vertical jumping performance in nordic combined athletes. J Sports Med Phys Fitness 41: 354-361.

21. Bangsbo J, Mohr M, Poulsen A, Perez-Gomez J, Krustrup P (2006) Training and testing the elite athlete. J Exerc Sci Fit 4: 1-14.

22. Muaidi Q, Nicholson LL, Refshauge KM (2009) Do elite athletes exhibit enhanced proprioceptive acuity, range and strength of knee rotation compared with nonathletes? Scand J Med Sci Sports 19: 103-112

23. Wong DP, Chaouachi A, Dellal A, Smith AW (2012) Comparison of ground reaction forces and contact times between 2 lateral plyometric exercises in professional soccer players. Int J 317 Sports Med 33: 647-65.

24. Hirayama K, Iwanuma S, Ikeda N, Yoshikawa A, Ema R, Kawakami Y (2017) Plyometric training favors optimizing muscle-tendon behavior during depth jumping. Front Physiol.

25. de Hoyo M, de la Torre A, Pradas F, Sañudo B, Carrasco L et al (2015) Effects of eccentric overload bout on change of direction and performance in soccer players. Int J Sports Med 36: 308-314. [crossref]

26. Sheppard JM1, Young WB (2006) Agility literature review: classifications, training and testing. J Sports Sci 24: 919-932. [crossref]
27. Gonaus C, Müller E (2012) Using physiological data to predict future career progression in 14- to 17 -year-old Austrian soccer academy players. J Sports Sci 30: $1673-1682$

28. Cometti G, Maffiuletti NA, Pousson M, Chatard J-C, Maffulli N (2001) Isokinetic strength and anaerobic power of elite, subelite and amateur French soccer players. Int J Sports Med 22: 45-330 51.

29. Wisløff U, Helgerud J, Hoff J (1998) Strength and endurance of elite soccer players. Med Sci Sports Exerc 30: 462-467. [crossref]

30. Barber-Westin SD, Noyes FR (2011) Factors used to determine return to unrestricted sports activities after anterior cruciate ligament reconstruction. Arthroscopy 27: $1697-1705$.

31. Hall MP, Paik RS, Ware AJ, Mohr KJ, Limpisvasti O (2015) Neuromuscular evaluation with single-leg squat test at 6 months after anterior cruciate ligament reconstruction. Orthop J 337 Sports Med 3: 2325967115575900

32. Petersen W, Taheri P, Forkel P, Zantop T (2014) Return to play following ACL reconstruction: a systematic review about strength deficits. Arch Orthop Trauma Surg 134: 1417-1428. [crossref]

\section{Citation:}

Fischer F, Gföller P, Hoser C, Gatterer H, Raschner C, Fink C (2018) Functional Assessment for Decision-Making Regarding Return to Sports Following ACL Reconstruction: A Comparison of Football Players with Normative Data. Integr J Orthop Traumatol Volume 1(1): 1-6. DOI: 10.31038/IJOT.2018102 